\title{
Labyrinthe
}

4 | 1999

Numéro 4

Mise en perspective

\section{Archéologie contemporaine et archéologie du catholicisme récent}

\section{Philippe Bruneau}

\section{(2) OpenEdition}

Journals

Édition électronique

URL : http://journals.openedition.org/labyrinthe/289

DOI : 10.4000/labyrinthe.289

ISSN : 1950-6031

Éditeur

Hermann

Édition imprimée

Date de publication : 1 octobre 1999

Pagination : $57-58$

\section{Référence électronique}

Philippe Bruneau, «Archéologie contemporaine et archéologie du catholicisme récent », Labyrinthe [En ligne], 4 | 1999, mis en ligne le 18 février 2005, consulté le 21 septembre 2020. URL : http:// journals.openedition.org/labyrinthe/289; DOI : https://doi.org/10.4000/labyrinthe.289

Ce document a été généré automatiquement le 21 septembre 2020.

Propriété intellectuelle 


\title{
Archéologie contemporaine et archéologie du catholicisme récent
}

\author{
Philippe Bruneau
}

1 Dans son principe, comme foi au transcendant et fréquentation personnelle de la divinité, une religion ne requiert ni bâtiment spécialement construit, ni vêtement particulier, ni imagerie, en un mot aucun artifice, aucun équipement technique. Mais, en fait, la plupart des religions s'équipent, et souvent profusément.

2 C'est le cas du catholicisme, et non sans effet, car l'équipement affecte la croyance, l'image informant l'idée qu'on se fait de l'invisible; et le culte, car l'église fait l'Église, le bâtiment ecclésial fait l'assemblée tout autant que l'inverse. Et de surcroît, le catholicisme n'échappant jamais à la diaschize sociale en dépit de son nom et de son parti universaliste, l'équipement, dans la France du XIX et du XXe siècle, offre l'intérêt de porter l'empreinte d'implications politiques, soit royalistes, soit nationalistes.

Pourtant, ce catholicisme, non pas proclamé ou vécu, mais outillé, est scientifiquement négligé au double profit de la recherche sur l'histoire de la pensée chrétienne ou sur la sociologie de l'Église. Ce cas est loin d'être isolé. Pour une raison très claire : notre humanité ne tient pas seulement à la faculté de construire l'univers de mots qui constitue le langage et de vivre en une société où chacun tient son rang et son rôle propres, mais aussi à la faculté technique d'avoir prise sur le monde par la médiation de l'outil ; en un mot, il n'est pas seulement en nous un homo sapiens ou loquens et, comme disait Aristote, un zôon politikon (exactement : un animal citoyen), mais un homo faber. Or, si maintes disciplines - telles, respectivement la philologie et la philosophie, l'histoire et la sociologie - s'occupent avec diligence du premier et du second, le troisième n'a toujours pas trouvé preneur universitaire. C'est l'archéologie, selon nous, qui a les meilleurs atouts pour jouer ce rôle, non plus définie par la pratique de la fouille comme on s'est pris à le faire en privilégiant les conditions de l'observation au détriment de l'objet d'étude, mais entendue comme investigation de tout l'équipement fabriqué ${ }^{1}$. 
Dès lors qu'on la rend ainsi comptable des produits d'une faculté technique partagée par tous les hommes, de quelque temps et de quelque lieu qu'ils soient, l'archéologie ne peut plus se confiner dans l'étude du seul passé reculé. Aussi, en 1978, avons-nous créé à l'Université de Paris-Sorbonne, outre un centre de recherches, un enseignement d'" archéologie moderne et contemporaine " qui fonctionne du DEUG au doctorat. Au même titre que l'archéologie industrielle, agricole ou vestimentaire, l'archéologie du catholicisme français récent n'est en théorie qu'un secteur, entre autres, de cette vaste archéologie contemporaine ; mais dans notre pratique c'est elle, avec l'archéologie funéraire, qui s'est trouvée au premier rang de nos préoccupations ${ }^{2}$. C'est dans ce cadre que se situe l'enquête mariale de Marie-Laure Portal.

\section{NOTES}

1.Sur cette redéfinition de l'archéologie et sur la théorie « artistique » qu'elle requiert, cf. P. Bruneau et P.-Y. Balut, Artistique et archéologie, Paris, Presses de l'Université de Paris-Sorbonne, 1997.

2.Une douzaine de contributions ont paru dans RAMAGE (Revue d'archéologie moderne et d'archéologie générale), fascicules 1 à 13 . Voir aussi P. Bruneau, « Un secteur clé de l'archéologie contemporaine : l'archéologie du catholicisme récent ", Annales d'histoire de l'art et d'archéologie [de l'Université libre de Bruxelles], 14 (1992), p. 75-91, où sont spécialement considérés les rapports du catholicisme et de la politique tels qu'ils se révèlent dans l'équipement ecclésial. Sur l'archéologie funéraire, voir les articles de P.Y. Balut dans les fascicules 1, 3-6 et 9 de RAMAGE.

\section{AUTEUR}

\section{PHILIPPE BRUNEAU}

Professeur à l'Université de Paris-Sorbonne 